\title{
Determinants of patterns of maternal and child health service utilization in a rural community in south eastern Nigeria
}

\author{
C. C. Agunwa*, I. E. Obi, A. C. Ndu, I. B. Omotowo, C. A. Idoko, A. K. Umeobieri and E. C. Aniwada
}

\begin{abstract}
Background: Women and children constitute a large proportion of any population. They are the most vulnerable to morbidity and mortality especially in developing countries. In many situations the problem of poor maternal and child health stems from the poor use of available services even when they are not of optimum quality. This study seeks to describe the patterns of utilization of Maternal and Child health $(\mathrm{MCH})$ services in a rural area of Enugu State, and identify factors that are associated with and responsible for determining them.

Methods: The study used a cross sectional analytic design. Pretested semi structured questionnaires were administered by interviewers to 602 women from a rural community in Enugu state, South east Nigeria. Two focus group discussions (FGDs) involving 8-10 men/ women each were conducted to identify factors affecting service utilization. Chi square analysis was done to identify factors associated with Maternal and Child Health services utilization. Logistic regression was used to identify determinants of utilization patterns. $N$ vivo software was used to analyze findings of the FGDs.
\end{abstract}

Results: The study revealed that increasing age, educational level, monthly income, number of children and occupation of both women and their husbands were associated with increased $\mathrm{MCH}$ service utilization. Average monthly income (OR: 1.317, $p=0.048$, Cl: 0.073-0.986) and number of children (OR: 1.196, $p<0.01, \mathrm{Cl}: 1.563-7.000$ ) were determinants of increased use of child care services while educational level (OR: 0.495, $p<0.001, \mathrm{Cl}$ : 1.244-2. 164) and age (OR: $0.115, p<0.001, \mathrm{Cl}: 0.838-0.948)$ determined better use of delivery and family planning services respectively.

Conclusions: Improved use of MCH services is related to socio economic challenges women face such as illiteracy and low income. Furthermore, the way health facilities and their staff are perceived by rural women affect how they use some of these services and should be considered in programs which seek to reduce maternal and child mortality. Behavioral change programs with high local content need to be implemented within rural areas especially among younger, illiterate women .

Keywords: Maternal and child services, Utilization, Rural women, Factors

\footnotetext{
*Correspondence: chukaagunwa@gmail.com

Department of Community Medicine, University of Nigeria/University of

Nigeria Teaching Hospital, Ituku Ozalla Campus, Enugu, Enugu State, Nigeria
} 


\section{Background}

Every year, more than 200 million women become pregnant, $15 \%$ of which are at risk of complications that have the potential to cause disease and death [1]. These risks exist in different societies and situations [2].

Persistently low utilization rates of Maternal and Child health $(\mathrm{MCH})$ services in developing countries [3, 4], have led some authors to the conclusion that programs that rely only on ANC as a delivery system are likely to have poor coverage and compliance [5]. Alternative delivery approaches need to be identified as maternal and child mortality rates are unacceptably high in most developing countries, particularly in Sub Saharan Africa [6].

In Nigeria, only $38.1 \%$ of women receive skilled attendance at delivery and immunization coverage ranges between $43 \%$ and $16 \%$ in urban and rural areas [7] while $25 \%$ of children are fully immunized at age 23 months [7] in a country where the service has been almost completely free since its inception.

Continued ignorance about the factors that determine the health care choices women make for themselves and their children will lead to a continuation of the waste of already limited resources and already embarrassing mortality figures. Unless the factors responsible for observed service utilization patterns in rural areas of developing countries are identified it will be difficult to properly intervene to correct the discrepancy in health service supply and demand which occurs in Nigeria and other developing countries.

This study seeks to describe the patterns of utilization of maternal and child health $(\mathrm{MCH})$ services (Family planning, Antenatal care, skilled delivery, child immunization and Child outpatient) in rural areas, and identify factors that are significantly associated with and responsible for determining them.

\section{Methods}

This cross sectional analytic study was carried out in 2013 with 610 women of reproductive age who reside in rural communities of Enugu State. Only females aged 15-49 years who had resided for at least a year in the study area irrespective of their marital or gestational status who gave consent and available were included in the study. Ethical clearance was obtained from the Enugu State Research Ethics Committee at the State Ministry of health.

Multistage sampling technique was utilized to select the sample. In the first stage, one (Nkanu East) out of the 14 rural local government areas in Enugu State was selected. In the second stage, Nara community with a population of 10,446 was selected. Each stages of selection was carried out by the simple random sampling technique of balloting. Within the community, the number of houses recorded under the house numbering system, 1931 in number, was ascertained from the State headquarters of the National Population Commission. This was divided by the sample size (602) to give a sampling interval of 3 . The index compound was selected also by balloting and subsequently, based on the sampling interval other compounds were selected. Within each compound women who met the inclusion criteria were interviewed. Where there were more than one eligible woman in the compound, one was selected by ballot.

Data was collected using an interviewer administered, semi structured questionnaire. The questionnaire was translated into the local language and pretested in a similar rural community, following which ambiguous questions were simplified. The questionnaire contained questions on the socio demographic characteristics of respondents, their level of utilization of the different $\mathrm{MCH}$ services, their reasons for using/not using them, and their experiences at the health center. They were administered by 4 trained interviewers; the average time of administration was $30 \mathrm{~min}$. Data was checked at the end of each day by the authors and if any data was missing the interviewers returned to the household for it, where possible.

SPSS for windows version 18 (Chicago) was used for data entry and analysis. The $\mathrm{MCH}$ service utilizations of interest were attendance to antenatal clinic, delivery in a health facility, use of any family planning method, use of outpatient treatment of common childhood illnesses and uptake of immunization appropriate for child's age (based on the national program on immunization). Descriptive analysis were expressed as percentages. Statistical testing was done using Chi square analysis and variables which had significant association with 1 or more service utilizations were entered into the regression model. Statistical significance was considered present at $p$ value less than 0.05 . Only respondents who were eligible for a $\mathrm{MCH}$ service were considered in calculation of utilization levels.

\section{Results}

Table 1 shows that the categories of respondents with the greatest frequency were those aged 25-29 years; $160 / 602(26.7 \%)$ with mean age (SD) of 27.2 years (6.7), those with secondary level of education $382 / 602$ (63.7\%), those who were married, 520/602 (86.4\%), and unemployed; $242 / 602$ (40.2\%). The most prevalent occupation among their husbands was civil service; 174/602 (32.7\%).

Table 2 shows most women had 1-4 children 404/ 602 (67.1\%) and had a history of having ever lost a pregnancy 468/602 (77.7\%).

Table 3 shows low level of use of family planning (FP) and institutional delivery (ID) across most age groups, 
Table 1 Socio demographic characteristics of respondents

\begin{tabular}{|c|c|}
\hline Variable & Freq (\%) \\
\hline \multicolumn{2}{|l|}{ Age group (years) } \\
\hline $15-19$ & $108(18.0)$ \\
\hline $20-24$ & $124(20.7)$ \\
\hline $25-29$ & $160(26.7)$ \\
\hline $30-34$ & $124(20.7)$ \\
\hline $35-39$ & $54(9.0)$ \\
\hline $40-44$ & $20(3.3)$ \\
\hline$\geq 45$ & $10(1.7)$ \\
\hline Mean $\left(\mathrm{SD}^{*}\right)$ & $27.2(6.66)$ \\
\hline $95 \%$ C.I. ${ }^{*}$ & $14.1-40.3$ \\
\hline Range & $15-49$ \\
\hline \multicolumn{2}{|l|}{ Educational level } \\
\hline None & $12(2.0)$ \\
\hline Primary & $72(12.0)$ \\
\hline Secondary & $382(63.7)$ \\
\hline Tertiary & $134(22.4)$ \\
\hline \multicolumn{2}{|l|}{ Marital status } \\
\hline Married & $520(86.4)$ \\
\hline Single & $62(10.3)$ \\
\hline Widowed & $20(3.3)$ \\
\hline \multicolumn{2}{|l|}{ Occupation: } \\
\hline Unemployed & $242(40.2)$ \\
\hline Trader & $166(27.6)$ \\
\hline Civil servant & $156(25.9)$ \\
\hline Artisan & $20(3.3)$ \\
\hline Farmer & $14(2.3)$ \\
\hline Student & $4(0.7)$ \\
\hline Husband's Occupation & $n=520$ \\
\hline Civil Servant & $174(33.5)$ \\
\hline Artisan & $170(32.7)$ \\
\hline Trader & $76(14.6)$ \\
\hline Farmer & $38(7.3)$ \\
\hline Professional eg. Doctor, Lawyer & $36(6.9)$ \\
\hline Pensioner & $26(0.1)$ \\
\hline
\end{tabular}

${ }^{*} \mathrm{Cl}$ Confidence interval, SD Standard deviation

especially in the youngest age groups between 15 and 24 years. There was significant association between age and use of all services except Child Out patient Department (COPD). ( $p<0.0001$ for family planning, ANC and Immunization and $p=0.001$ for delivery services).

There was higher level of use of family planning, child outpatient (OPD) and institutional delivery services among educated women compared with non-literate women. There was also better utilization of ANC,
Table 2 Respondents pregnancy history

\begin{tabular}{ll}
\hline Variable & Freq (\%) \\
& $N=602$ \\
\hline No of children & \\
$\quad$ None & $74(12.2)$ \\
$1-4$ & $404(67.1)$ \\
$>4$ & $124(20.7)$ \\
Ever lost a pregnancy? & \\
Yes & $468(77.7)$ \\
No & $134(22.3)$ \\
\hline
\end{tabular}

immunization and delivery services (476/602; 79.0\%, 593/602; 98.5\% and 272/602; 45.2\% respectively) among women with tertiary education when compared with their other educated contemporaries. Family planning use was generally poor among all respondents. There was significant association between educational level and use of delivery $(p<0.001)$ and family planning $(p=0.05)$ services.

Table 4 reveals a high level of use of $100 \%$ in ANC, Immunization and COPD services among farmers but less of Family planning services (28.6\%) and none reported to have utilized institutional delivery services. Also worthy of note was the fact that unemployed women consistently had one of the lowest utilization figures and civil servants had consistently average to high rates compared to other groups. A significant association was found between occupation and the use of ANC $(p=0.02)$ and institutional delivery services $(P=0.03)$.

Table 4 also shows use of ANC and immunization services (100\%) among women whose husbands were farmers. There are generally high utilization rates for all services except family planning and delivery services. It also shows significant association between husbands' occupation and the use of institutional delivery and COPD services. $(P<0.001$ and $p=0.026$ respectively).

As shown in Table 5, a chi square analysis revealed that among those who used delivery and family planning services, the proportion of users was greatest in the groups which had good assessments of the local health facility and lowest among those that scored the facility "poor". This perception by the women was significantly associated with their utilization of delivery $(p=0.010)$ and family planning services $(p=0.047)$.

In Table 6, logistic regression identified average monthly income (OR: 1.317, $p=0.048, \mathrm{CI}: 0.073-0.986$ ) and number of children (OR: 1.196, $p<0.01$, CI: $1.563-7.000$ ) as determinants of increased use of child outpatient care. Educational level (OR: 0.495, $p<0.001$, CI: 1.244-2.164) was a determinant of increased use of delivery services and age (OR: $0.115, p<0.001, \mathrm{CI}: 0.838-0.948)$ was a determinant of increased use of family planning services. 
Table 3 Patterns of MCH service utilization among different age groups and levels of education

\begin{tabular}{|c|c|c|c|c|c|c|c|c|c|c|}
\hline \multirow[t]{2}{*}{ Variable } & \multicolumn{2}{|c|}{ ANC Freq (\%) } & \multicolumn{2}{|c|}{ Imm. Freq (\%) } & \multicolumn{2}{|c|}{ ID Freq (\%) } & \multicolumn{2}{|c|}{ FP Freq (\%) } & \multicolumn{2}{|c|}{ COPD Freq (\%) } \\
\hline & $\mathrm{T}$ & $n=504$ & $\mathrm{~T}$ & $n=528$ & $T$ & $n=464$ & $T$ & $n=602$ & $\mathrm{~T}$ & $n=512$ \\
\hline \multicolumn{11}{|c|}{ Age group (years) } \\
\hline $15-19$ & 16 & $12(75.0)$ & 20 & $8(40.0)$ & 0 & $0(0.0)$ & 44 & $2(4.5)$ & 10 & $6(60.0)$ \\
\hline $20-24$ & 34 & $34(100.0)$ & 36 & 36 100.0) & 52 & $12(11.5)$ & 56 & $2(3.6)$ & 36 & $34(94.4)$ \\
\hline $25-29$ & 116 & $116(100.0)$ & 124 & $112(90.3)$ & 124 & $56(22.6)$ & 136 & $16(11.8)$ & 120 & $110(91.7)$ \\
\hline $30-34$ & 144 & $142(98.6)$ & 148 & $142(95.9)$ & 144 & $88(30.6)$ & 160 & $30(18.8)$ & 148 & $140(94.6)$ \\
\hline $35-39$ & 108 & $104(96.3)$ & 114 & $106(93.0)$ & 104 & $22(21.2)$ & 116 & $44(37.9)$ & 112 & $104(92.9)$ \\
\hline $40-44$ & 56 & $56(100.0)$ & 56 & $52(92.9)$ & 56 & $26(46.4)$ & 60 & $34(56.7)$ & 56 & $46(82.1)$ \\
\hline$\geq 45$ & 30 & $30(100.0)$ & 30 & $30(100.0)$ & 26 & $10(38.5)$ & 30 & $20(66.7)$ & 30 & $28(93.3)$ \\
\hline$x^{2}$ & & 25.132 & & $41.730 f$ & & $21.864 f$ & & $55.483 f$ & & $10.732 f$ \\
\hline Df & & 6 & & 6 & & 6 & & 6 & & 6 \\
\hline$p$-value & & $<0.0001$ & & $<0.0001$ & & 0.001 & & $<0.0001$ & & 0.097 \\
\hline \multicolumn{11}{|c|}{ Level of education } \\
\hline None & 4 & $2(50.0)$ & 2 & $2(100.0)$ & 0 & $0(0.0)$ & 0 & $0(0.0)$ & 0 & $0(0.0)$ \\
\hline Primary & 86 & $72(83.7)$ & 90 & $88(97.8)$ & 92 & $20(21.7)$ & 96 & $34(35.4)$ & 0 & $0(0.0)$ \\
\hline Secondary & 288 & $242(84.1)$ & 270 & $268(99.2)$ & 286 & $60(21.0)$ & 328 & $68(20.7)$ & 280 & $34(12.1)$ \\
\hline Tertiary & 162 & $128(79.0)$ & 136 & $134(98.5)$ & 146 & $66(45.2)$ & 174 & $46(26.4)$ & 144 & $10(6.9)$ \\
\hline$x^{2}$ & & $3.341 f$ & & $3.874 f$ & & $16.158 f$ & & $11.365 f$ & & $7.594 f$ \\
\hline Df & & 5 & & 5 & & 5 & & 5 & & 5 \\
\hline$p$-value & & 0.648 & & 0.568 & & 0.006 & & 0.045 & & 0.180 \\
\hline
\end{tabular}

Where, $n$ number of women using MCH service, $T$ total number of women in the group

\section{Discussion}

Utilization of antenatal care (ANC) and immunization services for children were generally high with peak values in older women of 40 years and above and the lowest utilization rates in the 15-19 year age group. Women aged between 25 and 34 years were more likely to use antenatal, delivery, family planning and immunization services than those younger than 25 years with the lowest utilization rates found among women who were less than 20 years of age. Institutional delivery and family planning utilization were generally low, reaching its peak utilization rate among women older than 40 years. This may be attributed to their being more experienced and more enlightened in childbearing and child care activities. Also women are usually better empowered financially by this age giving them more freedom to take decisions and make personal choices they believe are in their best interest $[8,9]$. Age was identified as a determinant of family planning services among these women.

The utilization of family planning services was common among the educated groups of respondents. The consistently high $\mathrm{MCH}$ utilization rates among farmers is worthy of note and differs from findings in Malaysia where women whose husbands worked in business/service were more likely to seek treatment from a doctor or nurse compared with wives of farmers $(p<0.01)$ [10].
Utilization rates were highest among civil servants and consistently low among the unemployed. This supports previous findings about the influence of financial barriers on utilization of $\mathrm{MCH}$ services in developing countries [11].

Utilization of Institutional delivery services increased with and was found to have a significant association with husband's occupation reaching its highest rates where the husband was a professional or farmer. Significant association of husband's occupation with use of family planning and immunization services was also observed. The reason for this may be that in this part of the world where husbands tend to be sole decision makers and in which there is financial dependence on them by their wives, they have a strong influence on the health service utilization practices of their wives and so women with educated and/or wealthy husbands are better supported to adopt proper health seeking behaviors [10].

The study found, once again, an increase in the utilization of ANC, child care and delivery services with increasing level of education of the women themselves up to a peak among those with tertiary school education, and then a decline among nonliterate women. Education was also identified as a factor determining use of delivery services. A very similar pattern is seen in the utilization of Immunization, Family Planning and Institutional Delivery services and 
Table 4 Utilization of MCH services among different occupational groups

\begin{tabular}{|c|c|c|c|c|c|c|c|c|c|c|}
\hline \multirow[t]{2}{*}{ Variable } & \multicolumn{2}{|c|}{ ANC Freq (\%) } & \multicolumn{2}{|c|}{ Imm. Freq (\%) } & \multicolumn{2}{|c|}{ ID Freq (\%) } & \multicolumn{2}{|c|}{ FP Freq (\%) } & \multicolumn{2}{|c|}{ COPD Freq (\%) } \\
\hline & $\overline{\mathrm{T}}$ & $n=504$ & $\overline{\mathrm{T}}$ & $n=528$ & $\bar{T}$ & $n=464$ & $\bar{T}$ & $n=602$ & $\overline{\mathrm{T}}$ & $n=512$ \\
\hline \multicolumn{11}{|c|}{ Respondents occupation } \\
\hline Unemployed & 242 & $178(73.6)$ & 182 & $178(97.8)$ & 242 & $46(19.0)$ & 242 & $42(17.4)$ & 194 & $178(91.8)$ \\
\hline Trader & 166 & $152(91.6)$ & 150 & $150(100.0)$ & 166 & $48(28.9)$ & 166 & $50(30.1)$ & 154 & $138(89.6)$ \\
\hline $\mathrm{C} /$ servant & 80 & $130(83.3)$ & 132 & $130(98.5)$ & 156 & $46(29.5)$ & 156 & $48(30.8)$ & 136 & $130(95.6)$ \\
\hline Artisan & 20 & $16(80.0)$ & 16 & $16(100.0)$ & 20 & $4(20.0)$ & 20 & $2(10.0)$ & 18 & $14(77.8)$ \\
\hline Farmer & 14 & $14(100.0)$ & 14 & $14(100.0)$ & 0 & $0(0.0)$ & 14 & $4(28.6)$ & 14 & $14(100.0)$ \\
\hline Student & 4 & $4(100.0)$ & 4 & $4(100.0)$ & 4 & $4(100.0)$ & 4 & $2(50.0)$ & 4 & $2(50.0)$ \\
\hline$x^{2}$ & & $13.124 f$ & & $1.929 f$ & & $12.411 \mathrm{f}$ & & $8.296 f$ & & $9.118 f$ \\
\hline Df & & 5 & & 5 & & 5 & & 5 & & 5 \\
\hline$p$-value & & 0.022 & & 0.859 & & 0.030 & & 0.141 & & 0.104 \\
\hline \multicolumn{11}{|c|}{ Husbands Occupation } \\
\hline Unemployed & 0 & $0(0.0)$ & 0 & $0(0.0)$ & 0 & $0(0.0)$ & 0 & $0(0.0)$ & 0 & $0(0.0)$ \\
\hline Trader & 48 & $46(95.8)$ & 48 & $48(100.0)$ & 50 & $18(36.0)$ & 50 & $16(32.0)$ & 48 & $40(83.3)$ \\
\hline $\mathrm{C} /$ servant & 138 & $136(98.6)$ & 134 & $132(98.5)$ & 114 & $34(30.0)$ & 148 & $46(31.1)$ & 140 & $108(77.1)$ \\
\hline Artisan & 134 & $132(98.5)$ & 134 & $130(97.0)$ & 146 & 28 (19.2) & 146 & $46(31.5)$ & 138 & $112(81.2)$ \\
\hline Farmer & 12 & $12(100.0)$ & 12 & $12(100.0)$ & 14 & $6(42.9)$ & 12 & $2(16.7)$ & 14 & $10(71.4)$ \\
\hline Self employed & 82 & $82(100.0)$ & 82 & $82(100.0)$ & 84 & $20(23.8)$ & 84 & $16(19.0)$ & 84 & $70(83.3)$ \\
\hline Professional & 12 & 10(83.3) & 12 & $12(100.0)$ & 12 & $8(66.7)$ & 12 & $2(16.7)$ & 12 & $10(83.3)$ \\
\hline$x^{2}$ & & $13.751 \mathrm{f}$ & & $2.407 f$ & & $23.889 f$ & & $9.474 f$ & & $59.115 f$ \\
\hline Df & & 7 & & 7 & & 7 & & 7 & & 7 \\
\hline$P$ value & & 0.088 & & 0.966 & & 0.002 & & 0.304 & & 0.026 \\
\hline
\end{tabular}

Where, $n$ number of women using MCH service, $T$ total number of women in the group, C/servant civil servant

women without any formal education consistently had the lowest utilization rates for every service.

Also, there was significant association observed between education and use of all $\mathrm{MCH}$ services except OPD services. This pattern is similar to the findings of other authors [12] and may be due to the fact that with educational attainment comes increased awareness of health related information which predisposes one to better utilization of health services [13]. However, a limitation of the study may be the fact that some categories of education and occupation had no observations. Further studies may be required to support findings related to these characteristics.
What this implies is that the higher the literacy rate of any population the higher the rate of utilization of $\mathrm{MCH}$ services. There is therefore need to ensure access of women to basic education in order to increase national literacy rates in developing countries. The exception noticed in COPD utilization may be due to higher patronage of other non- formal care providers such as patent medicine vendors and chemists who are perceived as legitimate care givers by majority of society [14].

Increasing age and education level were associated with better utilization of immunization services while the reverse was the case with increasing monthly income and occupation, and surprisingly, number of children.

Table 5 Relationship between perception of the facility and MCH service utilization

\begin{tabular}{|c|c|c|c|c|}
\hline \multirow{3}{*}{$\begin{array}{l}\text { Assessment of health center/ } \\
\text { health staff }\end{array}$} & \multicolumn{2}{|c|}{$\underline{\text { Utilization of institutional delivery services }}$} & \multicolumn{2}{|c|}{ Utilization of family planning services } \\
\hline & Yes & No & Yes & No \\
\hline & $F(\%)$ & $F(\%)$ & $F(\%)$ & $F(\%)$ \\
\hline Poor $(0-6) n=532$ & $240(45.1)$ & $292(54.9)$ & $91(17.1)$ & $441(82.9)$ \\
\hline Good $(7-13) n=70$ & $55(78.6)$ & $15(21.4)$ & $18(25.7)$ & $52(74.3)$ \\
\hline$x^{2}$ & 15.924 & & 7.964 & \\
\hline$P$ value & 0.014 & & 0.047 & \\
\hline
\end{tabular}


Table 6 Significant determinants of MCH service utilization

\begin{tabular}{|c|c|c|c|c|c|}
\hline \multirow[t]{2}{*}{ MCH service } & \multirow[t]{2}{*}{ Variable } & \multirow[t]{2}{*}{ OR } & \multirow[t]{2}{*}{$P$ value } & \multicolumn{2}{|l|}{ 95\% C.I. } \\
\hline & & & & Lower limit & Upper limit \\
\hline \multirow[t]{6}{*}{ COPD } & Ag. Monthly income & & & & \\
\hline & $<\mathrm{N} 10,000$ & 1 & & & \\
\hline & $>100,000$ & 1.317 & 0.048 & 0.073 & 0.986 \\
\hline & No of living children & & & & \\
\hline & $1-4$ & 1 & & & \\
\hline & $>4$ & 1.196 & 0.002 & 1.563 & 7.000 \\
\hline \multirow[t]{3}{*}{ Delivery } & Educational level & & & & \\
\hline & Is not educated & 1 & & & \\
\hline & Has tertiary education & 0.495 & 0.000 & 1.244 & 2.164 \\
\hline \multirow[t]{3}{*}{ FP } & Age & & & & \\
\hline & Age $<20$ yrs & 1 & & & \\
\hline & Age $40-44$ yrs & 0.115 & 0.000 & 0.838 & 0.948 \\
\hline
\end{tabular}

The use of child care (outpatient and immunization) services increased with income but decreased with age. Delivery at formal institutions improved with better education, occupation and income earned supporting the idea that finance plays a role in choices made when deciding whether or not to utilize health services.

Age was found to be a significant determinant of family planning use with very poor patronage among women less than 20 years of age and increasing service utilization in subsequent older age groups. This supports the findings of the FGD which revealed the perception, especially among younger women, that family planning was meant only for women who had completed their families.

Occupation of women was found to have significant effect on service utilization. This is in keeping with findings of studies carried out in the Philippines [15] and Ghana [16] in which occupation was found to strongly influence use of maternal services with civil servants and other professionals found to be more likely to use $\mathrm{MCH}$ services. Nevertheless, contrasting findings have been reported in Kuwait [17] where the possession of a paying job was found not to have any influence on the use of Family planning and other $\mathrm{MCH}$ services by women. However the differences in the religious and cultural backgrounds for these studies may account for the differences in the results seen because in societies where gender equity and empowerment are not taken seriously, the ability of the educated woman to make health related choices and pay for services is still significantly constrained.

Use of these services generally increased with increasing number of pregnancies except use of child OPD services. This differs from the findings of other studies $[18,19]$ in which the proportion of women most likely to utilize maternal services decreased with increasing birth order. This may be due to increased confidence in health services with each successful delivery and is actually a welcome development considering the higher risk of maternal morbidity and mortality associated with increasing numbers of pregnancies.

Although the use of maternal and child services was found to be associated with the social classes of these women represented by average income, occupation and education, none of these factors proved to be a significant determinant of service use. Another study [20] also shows differences in the utilization rates for women in different socioeconomic levels, with women from lower levels being less likely to seek orthodox health care services than their counterparts from higher socioeconomic strata. It is also important to note that average monthly income which can be difficult to estimate in selfemployed individuals, may not be the best index of socio economic status and other indices such as property owned and education achieved may need to be used in future studies to further support these findings.

The utilization of maternal and child services was also found to be dependent on the perception of the health center/health staff by members of the community. A statistically significant association was identified between perception of the health facility and utilization of delivery and family planning services. This is similar to the findings of studies in Uganda [8], and the Dominican Republic [21]. In the Ugandan study, members of a tribe called "Alurs" do not usually attend ANC or deliver in the health center because of the embarrassment involved in being considered by other community members as being too weak to deliver without the assistance of a midwife. During this study, an informal interview with the Officer in charge of the health center revealed that a 
major factor which discouraged service use in the area was the cultural belief that women who delivered in the health center had been unfaithful to their husbands.

Women mentioned caring attitude of health workers as the major factor, affecting their patronage/non patronage of the health center. This was much more than those who considered the quality of care or even cost. Similar findings were observed in Bangladesh [22], Yemen [23] and studies in Nigeria and other African countries $[24,25]$ where underutilization of maternal and child services was attributed to the poor behavior of staff and preference for a more friendly atmosphere.

\section{Conclusion}

Key characteristics of rural women which play major roles in influencing their use of these services are age, education, number of children, occupation, income and their perception of health workers and the facility. The poor levels of utilization among women less than 20 years give cause for concern. It identifies them as a major target for future interventions aimed at achieving a change in attitude and subsequently an improvement in $\mathrm{MCH}$ service use. The influence of respondents' husbands on their use of services makes a strong case for increased male involvement in delivery of $\mathrm{MCH}$ services.

The provision of adequate numbers of properly trained health workers at well-equipped health facilities is essential, and if implemented will improve use of available services and contribute to reduction in maternal and child mortality rates.

\section{Abbreviations}

ANC: Antenatal Clinic; Cl: Confidence Interval; FGD: Focus Group Discussion; FP: Family Planning; ID: Institutional Delivery; $\mathrm{MCH}$ : Maternal and Child Health; OPD: Out Patient Department; OR: Odds ratio; SD: Standard Deviation; SPSS: Statistical Package for the Social Sciences

\section{Acknowledgements}

Not applicable.

\section{Funding}

There was no external funding received for this study. It was completely funded by the authors.

\section{Availability of data and materials}

All data generated during and/or analysed during the study are available from the corresponding author on reasonable request.

\section{Authors' contributions}

All authors participated in and approved the study design and data collection tool. ACC and OIE collected the data. ACC and AEC analysed the data. ACC,OIE,OIB, NAC, ICA, UAK and AEC developed the initial draft of the paper. All authors read and approved the final manuscript.

\section{Ethics approval and consent to participate}

Ethical clearance was obtained from the Medical Research Ethics Committee of the Enugu State Ministry of Health. Written consent was obtained from study participants before administration of the data collection tool (questionnaire).

\section{Consent for publication}

Not applicable.

\section{Competing interests}

The authors declare that they have no competing interests.

\section{Publisher's Note}

Springer Nature remains neutral with regard to jurisdictional claims in published maps and institutional affiliations.

Received: 14 November 2016 Accepted: 2 November 2017

Published online: 13 November 2017

\section{References}

1. Heron M, Sutton P, Xu J, Ventura SJ, Strobino DM, Guyer B. Annual summary of vital statistics. Pediatrics. 2010;125(1):4.

2. Warschburger $P$, Kroller K. Maternal perception of weight status and health risks associated with obesity in children. Pediatrics. 2009;124(1):60-8.

3. Ahmed S, Creanga AA, Gillespie DG, Tsui AO. Economic status, education and empowerment: implications for maternal health service utilization in developing countries. PLoS One. 2010;5(6)

4. Mbonye AK, Neema S, Magnussen P. Treatment seeking practices for malaria in pregnancy among rural women in Mukono District, Uganda. J Biosoc Sci. 2006:38:221-37.

5. Mrisho M, Obrist B, Schellenberg JA, Haws RA, Mushi AK, Mshinda $H$, et al. The use of antenatal and postnatal care: perspectives and experiences of women and health care providers in rural southern Tanzania. BMC Pregnancy and Child Birth. 2009:9(10):1186.

6. Federal Ministry of Health. unicef website. [Online].; 2008 [cited 2013 May 3. Available from: HYPERLINK. https://www.unicef.org/factoftheweek/index_ 50177.html.

7. Demographic N. Health Survey (NDHS)(2013). Household population and Housing characteristics. National Population Commission (NPC). Federal Republic of Nigeria, Abuja, Nigeria. 2013:11-29.

8. Kiwanuka SN, Ekirapa EK, Peterson S, Okui O, Hafizur RM, Peters D, et al. Access to and utilization of health Services for the Poor in Uganda: a systematic review of available evidence. Trans R Soc Trop Med Hyg. 2008; 102(11):1067-74.

9. Malhotra A, Mather M. Do schooling and work empower women in developing countries? Gender and domestic decisions in Sri Lanka. In sociological forum 1997. Dec 1 (Vol. 12, no. 4, pp. 599-630). Springer Netherlands.

10. Chakraborthy NM, Ataharul I, Chowdhury RI, Bari W, Akhter HH. Determinants of use of maternal health services in rural Bangladesh. Health Promotion Int. 2003;18(4):327-37.

11. Ameh C, Msuya S, Hofman J, Raven J, Matthai M, et al. Status of emergency obstetric care in six developing countries five years before the Millenium development goal targets for maternal and newborn health. PLoS One. 2012;7(12):49938.

12. Prata N, Passano P, Rowen T, Bell S, Walsh J, Potts M. Where are the (few) skilled birth attendants? J Health Popul and Nutr. 2011;29(2):81-91.

13. Greenaway ES, Leon J, Baker DP. Understanding the association between maternal education and use of health services in Ghana: exploring the role of health knowledge. J Biosoc Sci. 2012 Nov 1;44(06):733-47.

14. Okonkwo AD, Okonkwo UP. Patent medicines vendors, community pharmacists and STi Management in Abuja, Nigeria. Africa health. Science. 2010 Oct;3:253-65.

15. Kozhimannil KB, Valera AS, Ross-Degnan D. The population level impacts of a National Health Insurance Programme and franchise midwife clinics on achievement of prenatal and delivery care standards in the Philippines. Health Policy. 2009:92(1):55-64.

16. Yakong VN, Rush KL, Basset-Smith J, Bottorff JL, Robinson C. Womens experiences of seeking reproductive health care in rural Ghana:challenges for maternal health service utilization. J Adv Nurs. 2010;66(11):2431-41.

17. Al-Kandari HY. Al-Qashan. Maternal self efficacy of mothers of children with intellectual development disabilities, down syndrome and autism in Kuwait. Child Adolesc Soc Work J. 2010;27:21-39.

18. Babalola S, Fatusi A. Determinants of use of maternal health Services in Nigeria - looking beyond individual and household factors. BMC Pregnancy and Childbirth. 2009:9:43.

19. Fotso J, Ezeh AC, Essendi H. Maternal health in resource-poor urban settings: how does autonomy influence the utilization of obstetric care services. Reprod Health. 2009;6:9. 
20. Camacho A, Castro M, Kaufman R. Cultural aspect related to the health of Andean women in Latin America: a key issue for the progress towards the attainment of millenium development goals. Int J Gynaecol Obstet. 2006:94(3):357-63.

21. Foster J, Burgos R, Caceres R, Altamonte A, Perez LJ, Noboa FR, et al. A community based participatory research approach to explore community perceptions of the quality of maternal-newborn health services in the Dominican Republic. Midwifery. 2010;26(5):504-11.

22. Paul BK, Rumsey DJ. Utilization of health facilities and trained birth attendants for childbirth in rural Bangladesh: an emperical study. Soc Sci Med. 2002;54(12):1755-65.

23. Basaleem HO. Womens reproductive health seeking behaviour in four districs in Sana'a, Yemen; Qantitative and qualitative analysis. Journal of Commuinty medicine and. Health Educ. 2012;2:153.

24. Abdulraheem BI, Olapipo AR, Amodu MO. Primary health care services in Nigeria: critical issues and strategies for enhancing the use by the rural communities. J Public Health and Epidemiol. 2012 Jan 31:4(1):5-13.

25. Mannava P, Durrant K, Fisher J, Chersich M, Luchters S. Attitudes and behaviours of maternal health care providers in interactions with clients: a systematic review. Glob Health. 2015 Aug 15;11(1):36.

Submit your next manuscript to BioMed Central and we will help you at every step:

- We accept pre-submission inquiries

- Our selector tool helps you to find the most relevant journal

- We provide round the clock customer support

- Convenient online submission

- Thorough peer review

- Inclusion in PubMed and all major indexing services

- Maximum visibility for your research

Submit your manuscript at www.biomedcentral.com/submit
Biomed Central 